\title{
Impact of the Telephone Assistive Device (TAD) on stuttering severity while speaking on the telephone
}

Nola Chambers

University of the Witwatersrand

\begin{abstract}
There is extensive experimental evidence that altered auditory feedback (AAF) can have a clinically significant effect on the severity of speech symptoms in people who stutter. However, there is less evidence regarding whether these experimental effects can be observed in naturalistic everyday settings particularly when using the telephone. This study aimed to investigate the effectiveness of the Telephone Assistive Device ${ }^{\circledR}$ (TAD), which is designed to provide AAF on the telephone to people who stutter, on reducing stuttering severity. Nine adults participated in a quasi-experimental study. Stuttering severity was measured first without and then with the device in participants' naturalistic settings while making and receiving telephone calls (immediate benefit). Participants were then allowed a week of repeated use of the device following which all measurements were repeated (delayed benefit). Overall, results revealed significant immediate benefits from the TAD in all call conditions. Delayed benefits in received and total calls were also significant. There was substantial individual variability in response to the TAD but none of the demographic or speech-related factors measured in the study were found to significantly impact the benefit (immediate or delayed) derived from the TAD. Results have implications for clinical decision making for adults who stutter.
\end{abstract}

Key words: altered auditory feedback (AAF), telephone use, adults who stutter, telephone assistive device (TAD)

A Itered auditory feedback (AAF) is an umbrella term used to refer to manipulations of auditory feedback in the form of frequency (frequency altered feedback or FAF) or timing (delayed auditory feedback or DAF). Both types of AAF have been shown to produce immediate reductions in stuttering for a majority of adults who stutter in experimental settings, particularly in oral reading (Kalinowski, Armson, Mieszkowski, Stuart \& Gracco, 1993; Kalinow'ski, Stuart, Sark \& Armson, 1996; Macleod, Kalinowski, Stuạrt \& Armson, 1995; Sparks, Grant, Millay, Walker-Baston \& Hynan, 2002; Stuart, Kalinowski \& Rastatter, 1997), and to a lesser extent, in monologues (Antipova, Purdy, Blakely \& Williams, 2008) and scripted conversations (Armson, Kiefte, Mason \& DeCroos, 2006; Pollard, Ellis, Finan \& Ramig, 2009).

The exact mechanism of how AAF reduces stuttering is not well understood. However, the general consensus is that AAF reproduces the choral effect, where adults who stutter tend to show immediate and dramatic reductions in stuttering when speaking chorally, or in unison with another speaker (Kiefte \& Armson, 2008). Theories differ regarding the mechanisms underlying both the choral speech effect, and by extension, AAF. Early theories attributed the positive effects of choral speech and AAF to changes in the motor production of speech (Wingate, 1969; 1970) such as more active control of vocalization, reduced rate of speech, and changes in vocal intensity. Recent studies, however, have suggested that this motor hypothesis is over-simplistic and does not account for benefits derived under conditions of
AAF even at rapid speech rates (Kalinowski et al., 1993, 1996; McLeod et al., 1995; Sparks et al., 2002). More recent theories have attributed the effects of AAF to reducing auditory perceptual anomalies in those who stutter, particularly related to anatomical anomalies of the auditory temporal cortex (i.e., atypical rightward asymmetry of the planum temporale (PT); Foundas et al., 2004). Based on their physiological findings, Foundas and colleagues have proposed two subgroups within the stuttering population, those with typical (leftward) PT asymmetry, which they consider adaptive and therefore may respond to motor speech techniques alone, and those with atypical (rightward) PT asymmetry, which is a significant risk factor for developmental stuttering, which may be more responsive to treatment via AAF as demonstrated in their study.

All studies conducted to date with AAF have found significant individual variation in the benefits derived from AAF. However, it is not clear what factors contribute to this variation. One important potential factor is that of severity of stuttering. It is not yet clear what factors underlie the ultimate severity of stuttering in individuals who stutter, but these factors are no doubt varied and consist of a complex interaction between biological, emotional, and environmental variables. Given this complexity, researchers

Correspondence to:
Dr Nola Chambers
Department of Speech Pathology and Audiology
University of the Witwatersrand
Johannesburg South Africa
Email: Nola.Chambers@wits.ac.za

Email: Nola.Chambers@wits.ac.za 
have employed various measures of severity, which may include more or fewer of these variables in quantifying severity. Percentage syllables stuttered (\%SS) is frequently used as it simply quantifies the behavioural severity of stuttering. Behavioural studies investigating the relationship between AAF and stuttering severity have found conflicting findings. Sparks et al. (2002) demonstrated greater improvements in fluency under DAF in people with severe versus mild presentations of stuttering when reading at both normal and fast speech rates. In contrast, Armson et al. (2006) found greater benefits from AAF in formulated speech (i.e., not reading) in adults with mild stuttering compared to those with more severe stuttering at baseline.

Foundas et al. (2004) found that in their stuttering group, only those with atypical PT asymmetry demonstrated significant reductions in stuttering severity under conditions of DAF and that these participants were also the ones with the most severe presentations of stuttering at baseline. This finding could suggest that the atypical PT asymmetry is directly responsible for both the initial severity of stuttering as well as the ability of DAF to induce fluency. The authors acknowledge that it is also posșible that the difference between PT asymmetry groups is evidence of a ceiling effect in the ability of DAF to induce fluency (i.e., that DAF simply can improve severe stuttering more than mild stuttering). A second factor that is related to stuttering severity, that could affect an individual's response to AAF, may be the type of stuttering symptoms a person presents with. For instance, it is possible that those whose stuttering is characterised predominantly by silent blocks may derive less benefit from a device that can only alter feedback from an audible source. In addition, related to the discussion above, silent blocks tend to be associated with more severe presentations of stuttering and the length of blocks is directly factored into severity calculations of clinical measures of severity such as the Stuttering Severity Instrument - 3 (SSI-3; Riley, 1994). No studies appear to have examined this potential variable.

A third factor affecting one's response to AAF may be the degree of language proficiency or language familiarity in multilingual speakers. A clear language familiarity effect in fluent bi- and multilingual speakers under DAF has been demonstrated (Van Borsel, Sunaert \& Engelen, 2005) with participants demonstrating significantly slower speech rate and more speech disruptions when reading their less familiar languages under DAF. Van Borsel and colleagues relate this finding to increased reliance on auditory feedback when reading in less familiar languages. Hence, if the auditory feedback system is disrupted under conditions of DAF, greater disfluencies result. The authors go on to hypothesise that the corollary may be true in adults who stutter, that is, that DAF may be most beneficial for adults who stutter in their less familiar language where problems in auditory feedback may be most pronounced. It is possible that DAF might assist in normalising the auditory feedback system, thus reducing stuttering severity more in less familiar languages in those who stutter. It is important to note that language proficiency in bilingual adults who stutter is not independent from stuttering severity, with severity often reported to increase in less familiar languages (Jankelowits \& Bortz, 1996; Watt, 2000). The potentially beneficial effects of AAF on speakers' less familiar language is intriguing to consider in South Africa where many clients are treated in their second or third languages. There appears to be no literature to this author's knowledge regarding responses to AAF in multilingual speakers who stutter.

In their seminal review of the literature regarding the impact of AAF on stuttering severity, Lincoln and colleagues (2006) stated that more research regarding the impact of AAF devices in naturalistic, as opposed to experimental settings was essential for the field. In addition, Armson et al. (2006) have suggested that it is important to examine the effects of AAF, not only in naturalistic settings, but also using commercially available devices as specific devices may not have the capabilities of devices that are used in experimental studies. One naturalistic speaking context which many adults who stutter report to be extremely stress-provoking is the use of the telephone. James, Brumfitt and Cudd (1999) sampled the perceptions of 223 adults who stuttered regarding telephone use and found that the majority of their sample reported particular difficulty using the telephone.

Their results suggested that an inability to use the telephone effectively, constituted considerable restrictions in daily life activities for adults who stutter, restricting participation in both social and career-related activities. Interestingly, those participants with self-reported severe stuttering found telephone use to be more difficult than those with mild stuttering.

It is important to consider reasons why the telephone presents such challenges to people who stutter. James et al. (1999) found that the most frequently cited reason for difficulty speaking on the telephone as opposed to "face-to-face" conversations was the total reliance on speech to convey information, leading to an actual or perceived pressure to speak fluently and keep the conversation going. The inability to use nonverbal communication both to assist in conveying messages and gauging listener's responses, was also reported as being problematic and was reported to result in telephone partners being less understanding than face-to-face conversational partners. Finally, the fact that telephone conversations frequently required introductions and/or the exchange of specific information was also cited as a particular source of difficulty for respondents.

There are only a few studies to date that have addressed the 
potential therapeutic effects of AAF when speaking on the telephone and these have all been conducted using commercially available devices. The earliest documented study was conducted by Zimmerman, Kalinowski, Stuart and Rastatter (1997).

Their study examined the effect of AAF during scripted, 300syllable telephone conversations to various local businesses by nine participants. AAF with a 50 milli-second $(\mathrm{ms})$ delay and half octave downward shift was provided by the commercially available Casa Futura Fluency System, and was presented binaurally via a headset. The results showed a remarkable decrease in stuttering, on average 55\% under FAF and 60\% under DAF. Some participants reached near-zero stuttering frequency. The scripted nature of the telephone calls and the fact that telephone calls were made from a laboratory detract from the naturalistic conditions under which telephone calls are typically made and may have enhanced the reductions of stuttering severity.

A second study that included the use of an AAF device in a more naturalistic or therapeutic manner was conducted by Van Borsel, Reunes, and Van den Bergh (2003). In that study, nine adults were exposed to AAF in a variety of speaking situations also using the portable Casa Futura School DAF device for three months. Included in this exposure, the participants were required to use the telephone to make two telephone calls, one to another participant and one to a stranger in response to a newspaper advertisement, and to receive four telephone calls a month from the researchers who enquired about compliance. Several of the participants reported that using the device had reduced their fear of speaking on the phone and this had lead to its more frequent use. However, objective data relating to stuttering severity while talking on the telephone was not collected.

The authors noted that in other speaking conditions, specifically 'automatic speech, conversation, picture description and repeating, stuttering in the non-feedback conditions had markedly reduced following the three months of repeated exposure to AAF, suggesting carryover of benefit from exposure to AAF to speech without AAF. It is unknown if a similar carryover effect may occur with telephone calls.

O'Donnell, Armson and Keifte (2008) recently investigated the effectiveness of the in-the-ear SpeechEasy device on stuttering severity in situations of daily living, including the telephone. Seven participants took part in the study which included assessments incorporating laboratory and naturalistic measures of stuttering severity, both before and after 9-16 weeks of repeated exposure to the SpeechEasy in everyday situations. For the telephone conversations, weekly calls were made to the participants by one of the authors, who became familiar to the participants over the course of the study, as well as by unfamiliar research assistants.

Thus all calls recorded and analysed were received by the par- ticipants. Results indicated that all seven participants demonstrated reductions in percentage syllables stuttered (\%SS) when speaking on the telephone with the device, with individual mean reductions ranging from $20 \%$ to $94.4 \%$ when speaking to the experimenter (group mean $64.5 \% ; S D=22.9$ ), and $7.5 \%$ to $74.4 \%$ when speaking to the unfamiliar research assistants (group mean 55.1\%; SD = 22.3).

Finally, Bray and James (2009) recently published preliminary data on 5 participants who used the Telephone Assistive Device (TAD), the device investigated in the current study, in naturalistic telephone conversations. Descriptive data suggested a decreasing trend in \%SS between naturalistic phone calls made without the device and phone calls made with the device, although the responses were highly variable among participants. In addition, more positive feelings related to using the telephone were reported by most participants, even when limited benefit in terms of reductions of stuttering frequency was noted. It is important to note that no attempt was made to assess the effect of repeated practice making telephone calls versus the effect of the device itself on stuttering severity. However, the results of this study provide preliminary data to warrant further research with the TAD.

This study aimed to investigate the effects of the VA609 TAD developed by a South African company known as VoiceAmp®. The TAD incorporates the already existing technological architecture of the VA601i Fluency System, which is a portable unit that provides monaural or binaural AAF to people who stutter. This existing technology has been housed in a unique unit that connects to the telephone and delivers AAF monaurally through the telephone handset.

This new platform has a variety of additional capabilities to the VA601i portable system, such as a word prompting feature that is designed to assist those who present with severe blocks on initial sounds to initiate voicing when speaking on the telephone. The overall aim of the study reported here, was to assess the effectiveness of the TAD in a sample of adults who stutter when talking on the telephone in their natural environments. This aim was operationalised into the following objectives to determine: (1) the immediate and delayed benefit from the TAD following a week of repeated use (as well as the relationship between this delayed benefit and the amount of time spent using the device during that week); (2) the difference, if any, in the benefit derived from the TAD between making telephone calls versus receiving telephone calls; (3) the carryover of benefit, if any, from using the TAD to telephone calls without using the TAD; (4) the impact of initial speech variables (stuttering severity and type of symptoms) and demographic variables (first versus second language use and self-reported restrictions in telephone use prior to the study) on the immediate and delayed benefit derived from the TAD and, (5) the participants' perceptions of the TAD following a week's repeated use of the device. 


\section{METHOD}

\section{Design}

A quasi-experimental design was used for this study. All participants were assessed both without and then with the TAD while making and receiving telephone calls before and after one week's repeated use of the TAD in their natural environments. There was hence no control group and all participants took part in all parts of the study.

\section{Participants}

Nine participants were recruited from the Pietermaritzburg (PMB) and surrounding areas of Kwa-Zulu Natal (KZN). Inclusion criteria included the presence of developmental stuttering as determined by clinical interview and speech evaluation, no hearing difficulties by self-report, and access to a land-line on a regular, if not daily, basis. There were no exclusionary criteria based on gender, age, severity of stuttering, number of languages spoken, history of speech therapy, or previous exposure to AAF devices. This inclusive approach to participant recruitment resulted in a highly diverse participant pool, which is helpful when attempting to identify relationships between variables (such as language spoken on the telephone and benefit derived) but also reduces experimental control over extraneous variables. Three participants who took part in the study were receiving therapy. The majority of participants were not receiving therapy and were ultimately recruited via a newspaper advertisement with distribu- uvil local to PMB ( $n=6)$. One other participant was recruited by word of mouth. Ten participants volunteered to take part in the study; however, one was ultimately excluded on the basis of having additional communication problems associated with cerebral palsy and developmental delays. As a result of these concomitant difficulties, his data proved to be very difficult to score reliably and were therefore excluded from the analyses. The fact that hearing could not be objectively screened is considered a limitation of the study.

The general demographic characteristics of the nine participants are presented in Table 1 while stuttering characteristics and information related to therapy history and telephone use are presented in Table 2. The mean age of participants was 29.89 years $(S D=8.59)$, with a range from 21 to 46 years of age. $A$ wide range of educational levels was represented among the participants, from those without high school qualifications (P6) through to those with post-graduate degrees (P2). A range of occupations was reported, though it must be noted that occupations for some participants were severely constrained by their stuttering and did not reflect their educational ability or potential. Two participants (P3 and P7), both had the capacity and financial opportunity to attend university, but chose not to and were reportedly not in their preferred occupations. Two participants spoke English as a second language.

Table 1. Demographic characteristics of participants

\begin{tabular}{|c|c|c|c|c|c|c|c|}
\hline Participant & Age (years) & Gender & $\begin{array}{l}\text { Lan- } \\
\text { guage } \\
\text { used }\end{array}$ & Ethnicity & Education & Occupation & $\begin{array}{l}\text { Recruitment } \\
\text { source }\end{array}$ \\
\hline 1 & 28 & Male & Second & Zulu & Grade 12 & Hospital orderly & Therapist \\
\hline 2 & 41 & Male & First & Indian & MBA & $\begin{array}{l}\text { Marketing man- } \\
\text { ager }\end{array}$ & $\begin{array}{l}\text { Word of } \\
\text { mouth }\end{array}$ \\
\hline 3 & 25 & Female & First & Indian & $\begin{array}{l}\text { Computer di- } \\
\text { ploma }\end{array}$ & Admin clerk & $\begin{array}{l}\text { Advertise- } \\
\text { ment }\end{array}$ \\
\hline 4 & 34 & Male & First & Indian & BSc Engineer- & Engineer & Therapist \\
\hline 5 & 24 & Male & Second & Zulu & Student & Student & Therapist \\
\hline 6 & 46 & Male & First & Indian & Grade 9 & $\begin{array}{l}\text { Rural tuck shop } \\
\text { manager }\end{array}$ & $\begin{array}{l}\text { Advertise- } \\
\text { ment }\end{array}$ \\
\hline 7 & 26 & Male & First & Indian & Grade 12 & $\begin{array}{l}\text { Machine opera- } \\
\text { tor }\end{array}$ & $\begin{array}{l}\text { Advertise- } \\
\text { ment }\end{array}$ \\
\hline 8 & 21 & Male & First & White & Student & Student & $\begin{array}{l}\text { Advertise- } \\
\text { mént }\end{array}$ \\
\hline 9 & 24 & Male & First & Indian & BCom IT & IT assistant & $\begin{array}{l}\text { Advertise- } \\
\text { ment }\end{array}$ \\
\hline
\end{tabular}


Impact of the Telephone Assistive Device (TAD) on stuttering severity while speaking on the telephone

\begin{tabular}{|l|l|l|l|l|l|}
\hline \multicolumn{2}{|l|}{ Table 2. Stuttering characteristics of participants } \\
\hline Participant & SSI & SSI severity & Predominant speech symptoms & Therapy history & Telephone use \\
\hline 1 & 38 & Very severe & Sound, syllable and word repetitions & $\begin{array}{l}\text { Current, none as } \\
\text { child }\end{array}$ & $\begin{array}{l}\text { Social and voca- } \\
\text { tional }\end{array}$ \\
\hline 3 & 19 & Mild & $\begin{array}{l}\text { Syllable and word repetitions, interjec- } \\
\text { tions }\end{array}$ & Brief as child & $\begin{array}{l}\text { Social and voca- } \\
\text { tional }\end{array}$ \\
\hline 4 & 45 & Very severe & Silent blocks, interjections & Brief as child & Family only \\
\hline 5 & 16 & Very mild & Sound, word and phrase repetitions & Brief as child & $\begin{array}{l}\text { Social and voca- } \\
\text { tional }\end{array}$ \\
\hline 6 & 23 & Mild & $\begin{array}{l}\text { Sound, syllable and word repetitions, } \\
\text { prolongations }\end{array}$ & $\begin{array}{l}\text { Current, none as } \\
\text { child } \\
\text { tional }\end{array}$ \\
\hline 7 & 20 & Mild & $\begin{array}{l}\text { Sound, syllable and word repetitions, } \\
\text { interjections }\end{array}$ & Brief as child & $\begin{array}{l}\text { Social and voca- } \\
\text { tional }\end{array}$ \\
\hline 8 & 39 & Very severe & Silent blocks, interjections & Brief as child & Social only \\
\hline 9 & 10 & Very mild & Word repetitions, interjections & Brief as child & Social only \\
\hline a Stuttering Severity Instrument-3 (Riley, 1994) total score & Audible blocks, sound repetitions & Brief as child & $\begin{array}{l}\text { Some social, vo- } \\
\text { cational }\end{array}$ \\
\hline
\end{tabular}

It is clear from the data in Table 2 that the severity of stuttering, as measured by the SSI-3 (Riley, 1994), was bimodally distributed, with five participants presenting with mild to very mild stuttering in conversational speech and reading and four presenting with very severe stuttering. Only two participants were currently receiving therapy, and this was reported to be of brief duration, approximately 3-4 months prior to the start of the study. One of these (P5) had previous exposure to AAF via the VoiceAmp VA601i portable device. No others were receiving therapy at the time of the study, despite frequent severe presentations of stuttering. Most reported having received therapy as children, but few reported any positive gains from this therapy and they were unable to describe the nature of the intervention received.

Based on self-report, the participants could be categorised into those who demonstrated little to no restrictions in telephone use, defined as using the telephone in all aspects of their lives, includ ing social and vocational spheres $(n=5)$ and those that reported severe restrictions in telephone use that were long-standing (i.e., for at least the previous ten years; $n=4$ ). These participants reported only using the telephone to call friends, or in an even more restricted fashion, only family (P3). They also reported never answering the phone unless they knew the caller, and never making enquiry calls to strangers. The level of restriction in telephone use did not always correspond with stuttering severity in that one adult with mild stuttering fell into the severe restriction category, while one adult with severe stuttering fell into the no restriction category. The significant restrictions participants placed on their own telephone use also had implications for the procedures of this study, as these participants would not have been able to make any 'cold' enquiry calls for the purpose of the study as in the Zimmerman et al. (1997) study. All calls made during the study needed to therefore be individualised to each participant's comfort level and typical pattern of usage.

\section{Apparatus and setting}

The apparatus used was the VA609 TAD as this is the device most accessible to the South African population. There is also only one previous, preliminary study documenting its potential effectiveness with adults who stutter (Bray \& James, 2009). The $T A D$ is a unique device that connects directly to the telephone handset, where the handset microphone receives the user's voice signal. Once altered by the device, the signal is delivered monaurally through the earpiece of the handset to the user. The feedback is not heard by the telephone conversational partners. In addition, the voices of the telephone partners are not altered in any way. During the telephone tasks, the default settings of $56 \mathrm{~ms}$ delay and $304 \mathrm{~Hz}$ upward frequency shift characteristic of Programme 1 were used in order to assess the effectiveness of the device's standard settings. If participants expressed dissatisfaction with these settings, they were also exposed to Programme 2, characterised by a $90 \mathrm{~ms}$ delay and $530 \mathrm{~Hz}$ upward frequency shift. All participants chose to use Programme 1. Procedures took place in the participants' natural environments. Table 3 lists the venues for data collection for each participant. Four participants chose to collect data primarily at their places of work, five at home, and one at his university, where he was a residential student. Venues for data collection were chosen by the participants based on where their most frequent telephone use occurred, permission from employers, and where they had access to a landline, which was necessary for TAD connection. All calls were videoed for further analyses using measures described below. 
Three measures were used in this study:

i. Stuttering Severity Instrument-3 (SSI-3; Riley, 1994). The SSI-3 is a clinical measure used to quantify and characterise stuttering severity of each participant at the start of the study. The SSI-3 employs analysis of both a conversational speech sample of at least 300 syllables and a reading passage. Stuttering severity was calculated using the composite measures of percentage syllables stuttered (\%SS), average duration of the three longest blocks, and physical concomitants according to the standard scoring procedures of the SSI-3.

ii. Percentage syllables stuttered (\%SS). Commensurate with previous studies of AAF devices, the primary dependent variable used to quantify stuttering during the telephone tasks and to calculate the benefit derived from the TAD was \%SS. This measure has value as it provides a clear metric for comparison to previous studies. However, it must be noted that it is limited to quantifying the frequency of stutters and has no value in quantifying other aspects of severity such as type of symptom, length of blocks, which is captured by measures such as the SSI. All speech samples from the telephone calls were transcribed for analysis.

Stuttered syllables were defined as silent blocks, sound, syllable or word repetitions, prolongations or interjections (Armson et al., 2006). If more than one type of dysfluency occurred on a syllable (e.g., interjection + block + sound repetition at the beginning of a word), this was counted as one stuttered moment. The number of syllables in the intended message was calculated and $\% S S$ was calculated individually for made and received calls. A total \%SS was calculated to reflect a combination of the made and received calls, which was calculated by add ing the total number of stuttered syllables in each of the made and received calls and 1 dividing by the sum of the syllables in each call, in order to control for differences in the length of samples.

Benefit derived from the TAD was quantified as a mean percentage change value and was calculated as the differ- 6 ence in \%SS without and with the TAD within each condition as a percentage of the value in 8 the No TAD condition. and questionnaire was developed specifically for this study. During the week of repeated use of the TAD, participants were asked to use the log to document the number of calls made and received using the TAD, the approximate number of minutes of each telephone call, and to rate their speech for each call on a 5 point scale where 3 = typical for that situation; 4 a little better, and 5 much better for that situation; 2 a little worse and 1 much worse for that situation. At the end of the week, participants were also asked to give an evaluation of the device in terms of the following parameters: ease of use, comfort of use, whether they would recommend the device to others, and whether they would support further development of the device. They were asked to give suggestions for further development and any other general comments in an open-ended written questionnaire.

\section{Procedures}

Ethical approval for this study was granted prior to the start of the study from the University of the Witwatersrand, Human Research Ethics Committee (HREC) Non-Medical (protocol number H080103). Devices were loaned to the researcher at no cost for use in this study by the manufacturing company VoiceAmp. The company did not dictate any conditions or expectations regarding the study in exchange for this loan and provided no financial support or compensation related to the study. All devices were returned to the company at the end of the study. The following procedures were implemented for each participant:

i. Stuttering severity evaluation. Each participant received an initial stuttering severity evaluation. Included in this evaluation

Table 3. Venue and telephone partners for each participant

\begin{tabular}{|c|c|c|c|c|c|c|c|c|c|}
\hline \multirow[b]{4}{*}{$\begin{array}{l}\text { Partici- } \\
\text { pant }\end{array}$} & & \multicolumn{8}{|c|}{ Telephone partner } \\
\hline & & \multicolumn{4}{|c|}{ Initial assessment } & \multicolumn{4}{|c|}{ Final assessment } \\
\hline & & \multicolumn{2}{|c|}{ Without TAD } & \multicolumn{2}{|c|}{ With TAD } & \multicolumn{2}{|c|}{ Without TAD } & \multicolumn{2}{|c|}{ With TAD } \\
\hline & Venue & Made & Received & Made & Received & Made & Received & Made & Received \\
\hline 1 & Work & Therapist & Therapist & Iherapist & $\begin{array}{l}\text { Supervi- } \\
\text { sor }\end{array}$ & $\begin{array}{l}\text { Physio- } \\
\text { therapist }\end{array}$ & \begin{tabular}{|l|} 
Re- \\
searcher
\end{tabular} & $\begin{array}{l}\text { Physio- } \\
\text { therapist }\end{array}$ & Researcher \\
\hline 2 & Work & Enquiry & $\begin{array}{l}\text { Re- } \\
\text { searcher }\end{array}$ & Enquiry & $-a$ & Business & a & Business & Business \\
\hline 3 & Home & Father & . a & Brother & Father & $\begin{array}{l}\text { Brother, } \\
\text { Father }\end{array}$ & . $a$ & $\begin{array}{l}\text { Mother, } \\
\text { brother }\end{array}$ & Researcher \\
\hline 4 & Home & $\begin{array}{l}\text { Friend, } \\
\text { enquiry }\end{array}$ & $\begin{array}{l}\text { Re- } \\
\text { searcher }\end{array}$ & Sister & Enquiry & Friend & Friend & Friend & Researcher \\
\hline 5 & $\begin{array}{l}\text { Univer- } \\
\text { sity }\end{array}$ & $\begin{array}{l}\text { Re- } \\
\text { searcher }\end{array}$ & $\begin{array}{l}\text { Re- } \\
\text { searcher }\end{array}$ & $\begin{array}{l}\text { Re- } \\
\text { searcher }\end{array}$ & $\begin{array}{l}\text { Re- } \\
\text { searcher }\end{array}$ &.$a$ & $\begin{array}{l}\text { Re- } \\
\text { searcher }\end{array}$ & a & Researcher \\
\hline 6 & Work & Enquiry & $\begin{array}{l}\text { Re- } \\
\text { searcher }\end{array}$ & Friend & $\begin{array}{l}\text { Re- } \\
\text { searcher }\end{array}$ & Business & \begin{tabular}{|l|} 
Re- \\
searcher
\end{tabular} & Business & Researcher \\
\hline 7 & Home & Friend & $\begin{array}{l}\text { Re- } \\
\text { searcher }\end{array}$ & Friend & $\begin{array}{l}\text { Re- } \\
\text { searcher }\end{array}$ & Friend & $\begin{array}{l}\text { Re- } \\
\text { searcher }\end{array}$ & Friend & Researcher \\
\hline 8 & Home & Gran & $\begin{array}{l}\mathrm{Re}- \\
\text { searcher }\end{array}$ & Sister & $\begin{array}{l}\mathrm{Re}- \\
\text { searcher }\end{array}$ & Enquiry & Gran & Enquiry & Aunt \\
\hline 9 & Work & $\begin{array}{l}\text { Gran, } \\
\text { mother }\end{array}$ & $\begin{array}{l}\mathrm{Re}- \\
\text { searcher }\end{array}$ &.$a$ & $\begin{array}{l}\text { Re- } \\
\text { searcher }\end{array}$ & $\begin{array}{l}\text { Re- } \\
\text { searcher }\end{array}$ & Business & $\begin{array}{l}\text { Re- } \\
\text { searcher }\end{array}$ & Researcher \\
\hline
\end{tabular}


Impact of the Telephone Assistive Device (TAD) on stuttering severity while speaking on the telephone

was an interview that tapped information regarding stuttering development and therapy history, and questions related to the frequency of typical telephone use. This information was therefore gained only by self-report.

\section{ii. Baseline telephone tasks without the TAD. For a baseline} measure, participants were asked to make and receive a telephone call without the TAD. Because each participant varied so much in terms of whom they would normally speak to on the telephone, they were at liberty to choose who they wanted to speak to within the limitations of the venue of data collection and time of day. Table 3 lists to whom and from whom the calls were made and received during the telephone tasks both before and after the week of repeated use. Where data collection took place at work; some participants were limited to calling within their organisation to limit telephone costs to the company. When it came to receiving calls, the researcher typically called the participant from another room or extension, or made use of serendipitous phone calls that took place during the data collection period. The lack of uniformity in terms of listener familiarity in this procedure may have affected the internal validity of the study. However, many of the participants with severely restricted telephone use would not have had the willingness or capacity to call a stranger or even a non-family member, particularly at the start of the study.

ili. Orientation to the $T A D$. Following the baseline telephone calls, participants were oriented to the TAD with a brief description of the principle behind the technology. The choral effect was explained and then demonstrated by reading or counting along with the participant and comparing this to their solo performance. Following this, each participant was given the opportunity to listen to the feedback provided by the TAD in a series of graded tasks including: counting, automatic speech, reading, giving their name 'and address, and answering some general questions regarding their family while holding the handset of the phone to their ear.

iv. Telephone tasks with the TAD. Following the orientation, participants were again required to make and receive at least one call using the TAD. Similar instructions to the baseline calls were given.

v. Repeated use in naturalistic environment. The TAD device was left in the participants' home or office environments for a week of repeated use. Participants were instructed to make and receive calls using the TAD in the normal course of their days and to complete the log sheet. As with the other self-report measures, the accuracy of this measure was not verified independently.

vi. Telephone tasks following the week of repeated use. At the end of the week, all telephone tasks were repeated (i.e., participants were required to make and receive a telephone call without the device and again with the device).

Inter-rater reliability

All telephone samples were videotaped and transcribed for analysis. Twenty-five percent of the telephone samples were randomly selected and analysed by a second coder in order to determine inter-rater reliability. The reliability coder was a qualified speech therapist who was blind both to the condition of each telephone call coded (i.e., with or without the TAD) and to whether it took place before or after the week's repeated use. Cohen's kappa (Cohen, 1960) was used to quantify agreement. Cohen's kappa assesses the reliability of a categorical scale while correcting for chance agreement and has values ranging from 0 to 1 . Values from .60 to .75 are regarded as good and values over .75 as excellent (Fleiss, 1981). A mean kappa of .80 (range .59 to .93) was obtained, indicating excellent agreement overall, despite a range of kappas between samples.

\section{Data Analysis}

Data were analysed according to the aims of the study. Due to the small sample size, non-parametric statistical procedures were used for all analyses (Siegel \& Castellan, 1988). Aims 1 to 3 required tests for related pairs and hence Wilcoxon signed rank tests for related pairs were used to determine whether changes or differences in \%SS were significant for immediate benefit, delayed benefit, differences in made versus received calls and carryover of delayed benefit with the TAD to calls without the TAD. In order to determine whether the total number of minutes of TAD use during the week of repeated use had any effect on the delayed benefit derived, Spearman's correlation coefficient between the total number of minutes and overall change in \%SS was calculated. For aim 4, the sample was divided into the appropriate independent groups (mild vs severe stuttering, presence or absence of silent blocks, low vs high restriction in telephone use, and first vs second language used) and \%SS was then compared across groups using a series of Mann-Whitney $U$ tests for both immediate and delayed benefit. Participants' perceptions of the TAD (aim 5) collected via the questionnaire were analysed through content analysis. In addition to the group statistics, individual trends were also examined in order to understand individual performances and differences more fully.

\section{RESULTS}

\section{Group Results}

Immediate benefit from the TAD. The individual and mean \%SS and standard deviations for each condition (made or received, with or without the TAD) both before and after the week of repeated use are presented in Table 4. On average, \%SS for the made calls during the initial evaluation decreased by $35 \%$, received calls by $36 \%$, and total calls by $32 \%$. According to the Wilcoxon signed ranks test for related samples, these changes were all statistically significant (made calls: $Z=2.21 ; p<.027 ; n=8$; received calls: $Z=2.02 ; p<.043 ; n=6$; total calls: $Z=2.31 ; p<.021$; $\mathrm{n}=9$ ). Following the week's use of the TAD, only the made calls condition showing a significant immediate decrease in \%SS when 
Nola Chambers

the TAD was used compared to the no TAD condition $(Z=2.21$; $\mathrm{p}<.027 ; \mathrm{n}=8)$, but not for received $(\mathrm{Z}=1.79 ; \mathrm{p}<.074 ; \mathrm{n}=7)$ or total calls $(Z=1.90 ; p<.058 ; n=9)$.

Table 4. Mean (SD) percentage syllables stuttered in each condition before and after week's use

\begin{tabular}{|c|c|c|c|c|c|c|c|c|c|}
\hline \multirow{2}{*}{ Participant } & \multicolumn{3}{|c|}{ Made } & \multicolumn{3}{|c|}{ Received } & \multicolumn{3}{|c|}{ Total } \\
\hline & No TAD & TAD & $\%$ Change & No TAD & TAD & \%Change & No TAD & TAD & \%Change \\
\hline & \multicolumn{9}{|c|}{ Before repeated use } \\
\hline 1 & 19 & 11 & 42 & 19 & $-b$ & $-b$ & 19 & 11 & 42 \\
\hline 2 & 16 & 12 & 25 & 8 & $-b$ & $-b$ & 11 & 12 & -9 \\
\hline 3 & 24 & 11 & 54 & $-b$ & 6 & $-b$ & 24 & 8 & 67 \\
\hline 4 & 16 & 7 & 56 & 21 & 8 & 62 & 18 & 8 & 56 \\
\hline 5 & 14 & 10 & 29 & 17 & 11 & 35 & 16 & 11 & 31 \\
\hline 6 & 10 & 3 & 70 & 13 & 5 & 62 & 12 & 4 & 67 \\
\hline 7 & 9 & 9 & 0 & 18 & 13 & 28 & 13 & 11 & 15 \\
\hline 8 & 8 & 8 & 0 & 15 & 15 & 0 & 12 & 13 & -8 \\
\hline 9 & 29 & $-b$ & $-b$ & 27 & 20 & 26 & 27 & 20 & 26 \\
\hline Mean & 16.11 & 8.88 & $34.50 *$ & 17.25 & 11.14 & $35.50 *$ & 16.89 & 10.89 & $31.89 *$ \\
\hline \multirow{2}{*}{$S D$} & 7.03 & 2.90 & 25.80 & 5.63 & 5.34 & 23.71 & 5.67 & 4.37 & 29.01 \\
\hline & \multicolumn{9}{|c|}{ After repeated use } \\
\hline 1 & 20 & 16 & 20 & 23 & 11 & 52 & 22 & 15 & 32 \\
\hline 2 & 11 & 2 & 82 & $-b$ & 7 & $-b$ & 11 & 4 & 64 \\
\hline 3 & 13 & 14 & -8 & $-b$ & 16 & $-b$ & 13 & 15 & -15 \\
\hline 4 & 12 & 8 & 33 & 15 & 15 & 0 & 13 & 11 & 15 \\
\hline 5 & $-b$ & $-b$ & $-b$ & 15 & 5 & 67 & 15 & 5 & 67 \\
\hline 6 & 16 & 4 & 75 & 19 & 3 & 84 & 18 & 4 & 78 \\
\hline 7 & 7 & 5 & 29 & 11 & 9 & 18 & 8 & 7 & 13 \\
\hline 8 & 16 & 14 & 13 & 9 & 13 & -44 & 10 & 13 & -30 \\
\hline 9 & 31 & 31 & 0 & 28 & 18 & 36 & 29 & 23 & 21 \\
\hline Mean & 15.75 & 11.75 & $30.50 *$ & 17.14 & 10.78 & 30.43 & 15.44 & 10.78 & 27.22 \\
\hline$S D$ & 7.29 & 9.36 & 32.67 & 6.69 & 5.17 & 43.44 & 6.62 & 6.42 & 37.05 \\
\hline
\end{tabular}

$\star p<.05$

a \% Change is calculated as the difference in conditions as a

percentage of initial value without TAD

- Dashes indicate missing data 
Delayed benefit from the TAD. To determine the delayed benefit of the TAD following the week's repeated use, changes in \%SS for each condition were examined from the initial assessment without the TAD to the final assessment with the TAD. Results are presented in Table 5. Wilcoxon signed ranks tests indicated that the delayed benefit was statistically significant for the received calls $(Z=2.52 ; p<.012 ; n=8)$, and total call conditions $(Z=2.55$; $p<.011 ; n=9)$ but not for the made calls $(Z=1.75 ; p<.080 ; n=8)$. On average, there was a $39 \%$ decrease in \%SS in delayed benefit for all calls. Significant individual variation is also evident in Table 5 and decreases in \%SS ranged from -75\% (stuttering frequency increased) to $+88 \%$ for the made calls condition, $13 \%$ to $77 \%$ for the received condition, and $-8 \%$ to $69 \%$ for the total condition.

Table 5. Delayed benefit from TAD: from initial assessment (no TAD) to final (TAD) assessment

\begin{tabular}{|c|c|c|c|c|c|c|c|c|c|}
\hline & \multicolumn{3}{|c|}{ Made } & \multicolumn{3}{|c|}{ Received } & \multicolumn{3}{|c|}{ Total } \\
\hline & $\begin{array}{l}\text { No } \\
\text { TAD }\end{array}$ & TAD & $\begin{array}{c}\% \text { Cha } \\
\text { ngea }\end{array} \mid$ & $\begin{array}{l}\text { No } \\
\text { TAD }\end{array}$ & TAD & $\begin{array}{c}\% \text { Cha } \\
\text { ngea }\end{array}$ & $\begin{array}{l}\text { No } \\
\text { TAD }\end{array}$ & TAD & $\begin{array}{c}\text { \%Change } \\
a\end{array}$ \\
\hline 1 & 19 & 16 & 16 & 19 & 11 & 42 & 19 & 15 & 21 \\
\hline 2 & 16 & 2 & 88 & 8 & 7 & 13 & 11 & 4 & 64 \\
\hline 3 & 24 & 14 & 42 & $-b$ & 16 & $-b$ & 24 & 15 & 38 \\
\hline 4 & 16 & 8 & 50 & 21 & 15 & 29 & 18 & 11 & 39 \\
\hline 5 & 14 & $-b$ & -0 & 17 & 5 & 71 & 16 & 5 & 69 \\
\hline 6 & 10 & 4 & 60 & 13 & 3 & 77 & 12 & 4 & 67 \\
\hline 7 & 9 & 5 & 44 & 18 & 9 & 50 & 13 & 7 & 46 \\
\hline 8 & 8 & 14 & -75 & 15 & 13 & 13 & 12 & 13 & -8 \\
\hline 9 & 29 & 31 & -7 & 27 & 18 & 33 & 27 & 23 & 15 \\
\hline Mean & 16.11 & 11.75 & \begin{tabular}{|c|}
27.2 \\
5 \\
\end{tabular} & 17.25 & 10.78 & \begin{tabular}{|c|}
41.0 \\
$0 *$
\end{tabular} & 16.89 & 10.78 & $39.00 *$ \\
\hline$S D$ & 7.03 & 9.36 & \begin{tabular}{|c|}
50.0 \\
5
\end{tabular} & \begin{tabular}{|l} 
\\
5.63 \\
\end{tabular} & 5.17 & \begin{tabular}{|c|}
24.0 \\
7
\end{tabular} & 5.67 & 6.42 & 26.14 \\
\hline \multicolumn{10}{|c|}{${ }^{*} p<.05$} \\
\hline \multicolumn{4}{|c|}{$\begin{array}{l}\text { a \%change is calculated as } \\
\text { percentage of initial value }\end{array}$} & \multicolumn{5}{|c|}{$\begin{array}{l}\text { the difference in conditions as a } \\
\text { without TAD }\end{array}$} & \\
\hline
\end{tabular}

The mean number of minutes spent using the TAD during the week of repeated use was 31.61 ( $S D=63.31$ ) for made calls, $4.67(S D=2.60)$ for received calls, and $36.33(S D=64.48)$ for total calls. The large standard deviations are as a result of one participant, P4, who used the TAD for substantially longer than the other participants, 208 minutes in total ( 200 for made calls and 8 minutes for received calls during the week of repeated use). This participant was particularly interested in knowing whether the TAD would improve his fluency on the telephone and used his phone extensively for personal and vocational use prior to the study. Without his data, the mean time spent using the TAD for the group was fairly low, only 10.56 ( $S D=4.85$ ) for made calls, $4.25(S D=2.44)$ for received calls, and $14.88(S D=3.91)$ for total calls across the whole week. Reasons for this were cited as ill- ness, lack of consistent access to a landline in the evenings, general dissatisfaction toward the end of the week with the TAD, and the general restriction in telephone use evident in many participants' lives. No significant relationships were observed between the minutes spent making calls with the TAD and benefit for made calls ( $r h o=.24 ; p<.57 ; n=8$ ); minutes spent receiving calls and benefit for received calls $(r h o=.08 ; p<.85 ; n=8)$ or total minutes spent using the TAD and total benefit ( $r h o=.36 ; p<.34 ; n=9$ ).

Table 6. Impact of speech and demographic variables on immediate and delayed benefit

\begin{tabular}{|c|c|c|c|c|}
\hline Variable & \multicolumn{2}{|c|}{ Immediate benefit } & \multicolumn{2}{|c|}{ Delayed benefit } \\
\hline & $Z^{a}$ & $p$ & $Z^{a}$ & $p$ \\
\hline $\begin{array}{l}\text { Initial stuttering sever- } \\
\text { ity: mild }(n=5) \text { vs severe } \\
(n=4)\end{array}$ & 0.87 & 0.39 & 0.74 & 0.46 \\
\hline $\begin{array}{l}\text { Silent blocks: present } \\
(n=6) \text { vs absent }(n=3)\end{array}$ & 0.39 & 0.7 & 0.52 & 0.6 \\
\hline $\begin{array}{l}\text { First }(n=7) \text { vs second } \\
(n=2) \text { language speaker }\end{array}$ & 0.15 & 0.88 & 0.44 & 0.66 \\
\hline $\begin{array}{l}\text { Restriction in telephone } \\
\text { use: low }(n=5) \text { vs high } \\
(n=4)\end{array}$ & 0.37 & 0.71 & 1.11 & 0.27 \\
\hline $\begin{array}{l}\text { aMann-Whitney Test for } \\
\text { two independent sam- } \\
\text { ples }\end{array}$ & & & & \\
\hline
\end{tabular}

Carryover of benefit to telephone calls without the TAD. Wilcoxon signed ranks tests indicated no significant benefit in calls made without the TAD following the week of repeated use for made calls $(Z=.21 ; p<.83 ; n=8)$, received calls $(Z=.85 ; p<.40$, $n=7)$, or total calls $(Z=.63 ; p<.53 ; n=9)$. This suggests that there was no carryover of benefit from using the TAD during the week to calls made without the TAD at the end of that week.

Impact of speech and demographic variables on benefit derived from the TAD. Aim 4 was concerned with the impact of speech variables (stuttering severity and presence of silent blocks at the initial evaluation) and demographic variables (use of first or second language on the telephone, and level of telephone use restriction reported by participants at the start of the study) on the immediate and delayed benefit derived from the TAD. A series of Mann-Whitney $U$ tests were calculated to investigate this aim, and the results are summarised in Table 6 above. None of the speech or demographic variables was significantly related to either immediate or delayed impact derived from the TAD. 
Participants' perceptions of the TAD. All the participants reported that the device was easy to use. On the 5-point Likert scale, participants tended to rate their speech with the TAD as the same or slightly better than usual with a mean of 3.93 $(S D=.38)$ and a range of 3.50 to 4.60 . Despite these largely positive ratings of telephone calls made with the TAD, three participants also reported that they found the device uncomfortable to use, with the predominant complaint being that the feedback was very distracting to them. Three participants also reported that they would not recommend the device to another person who stutters. However, most reported that they would support further development of the device. The most common developments suggested were adaptations for the device to be compatible with cordless and cellular phones, and voice prompts to assist with silent blocks. Voice prompting is technologically possible with the TAD, but was not assessed in this study.

Summary of group data. In summary, the group results suggest immediate benefits for the group as a whole in using the device for made, received, and total calls, despite clear individual variation. Delayed benefits were noted for received and total calls. The extent of benefit derived from the TAD appeared to bear no relationship with initial severity of stuttering, predominance of silent blocks, use of first or second language on the telephone, or level of restriction in telephone use reported by the participants at the start of the study. This complicates clinical decision making in the assessment of individual clients and in attempting to make prognoses as to who might benefit from the device. The individual profiles of three participants are described below in order to illustrate this individual variation more clearly.

\section{Individual Profiles}

Individual profiles of three participants who represent the heterogeneity in results are described to illustrate possible interactions between the variables examined in this study. P5 and P6 both demonstrated marked immediate benefit from the TAD device as well as the largest total percentage improvements in delayed benefits over the course of the study of $69 \%$ and $67 \%$ respectively (see Table 5). As expected from the group results above, however, these two participants differed markedly in nearly all aspects assessed in this study, including age ( 24 vs. 46 years), education (master's level student vs. grade 9), language used on the telephone (first vs. second), history of therapy, and previous exposure to AAF devices. However, P5 and P6 were similar in initial stuttering severity (mild), types of symptoms (sound, syllable and word repetitions, no silent blocks), and level of restriction in phone use (low). It is possible that an ideal response to the AAF provided by the TAD is to be found in a combination of variables rather than in any one variable in isolation. At the very least, the large disparity in the two participants who appeared to derive the greatest gains from the TAD would preclude clinicians from excluding any potential candidates from a trial period with the device, particularly based on any one of the demographic or speech variables considered in this study.

One other individual participant (P8) is worth mentioning as he appeared to gain no benefit from the TAD in either the immediate or delayed conditions. P8 presented with mild stuttering on the SSI-3 at his initial evaluation. During this evaluation, he reported that he considered his stuttering "cured" in conversational speech but that his stuttering was more severe when talking on the telephone and hence he demonstrated a significantly restricted use of the telephone at the start of the study. During the telephone tasks, it was observed that his stuttering was qualitatively more severe and was characterised by long silent blocks of up to 60 seconds as noted when calculating his \%SS. Very few other core behaviours other than these silent blocks were noted when he used the telephone. As mentioned, without any sound from the speaker, such as during a silent block, the TAD is unable to provide any feedback to assist in reducing stuttering. It is possible that for a client such as this, the voice prompting feature of the TAD would be beneficial.

\section{DISCUSSION}

Overall, the results of this study suggest that the TAD was effective in reducing stuttering severity as measured by \%SS for this group of adults who stutter while talking on the telephone. Participants' severity of stuttering decreased on average by $32 \%$ immediately using the TAD and by $39 \%$ after a week's repeated use with the TAD. These results are more modest than those reported by O'Donnell et al. (2008) who reported mean improvements in \% SS of $64.5 \%$ ( $S D=22.9)$ during calls received from the familiar experimenter and $55.1 \%(S D=22.3)$ during calls received by an unfamiliar research assistant. The results of the present study are also more modest than those of Zimmerman et al. (1997) who found immediate reductions in \%SS of $55 \%$ for FAF and $60 \%$ for DAF in scripted telephone conversations in 9 participants.

Methodological differences between these three studies could account for the differences in magnitude of benefit. One main difference was the instrumentation used. Participants in the Zimmerman et al. study were provided with binaural AAF provided through a headset with a boom microphone rather than a typical telephone handset. Stuart et al. (1997) have found greater benefits for binaural AAF than monaural AAF in experimental reading tasks. However, similar to the present study, participants in the O'Donnell study received monaural feedback through the in-theear portable SpeechEasy device. Participants in the O'Donnell study were, however, also using their devices in more speaking situations than the telephone and hence were being exposed to AAF through this device for much longer periods than the participants in this study.

With regard to participant characteristics, those in the Zimmerman et al. (1997) study had apparently all attended or been as- 
Impact of the Telephone Assistive Device (TAD) on stuttering severity while speaking on the telephone

sociated with the Total Immersion Fluency Training Program, suggesting a more extensive history of therapy than the participants in the present study. Similarly, the majority of participants in the O'Donnell study had previous exposure to AAF devices and the remaining two were referred from speech therapists, again suggesting a greater involvement in intervention than the current study's participants. As a result, it is possible that the participants in both these previous studies had less active avoidance of the telephone and less overall restriction in daily use of the telephone. The one week's use of the TAD in this study possibly did little to address the accumulated years of avoidance and anxiety associated with the telephone in a manner that would allow for the full fluency-enhancing benefits of the device to be seen.

This study found no carryover of the effects of TAD to calls made without the TAD in the final evaluation. This finding contrasts with that of Van Borsel et al. (2003) who found significant decreases in stuttered words in non-feedback conditions following three month's exposure to AAF compared to initial measures. It is possible that the discrepancy in findings is due to the shorter period of exposure in this study. Nonetheless, the present findings lend some weight to the assertion by Antipova et al. (2008) that AAF devices may be limited to use as prosthetics as opposed to a more permanent management strategy.

A finding in this study that is common to previous studies of AAF, was the presence of substantial individual variation in the participant's responses to AAF. This study found no explanation for this individual variation in initial stuttering severity, types of stuttering symptoms, initial level of restriction in telephone use, or use of first or second language on the telephone. It is likely that a combination of factors will ultimately predict who will benefit most from such a device. It is possible that only further neuroimaging studies will shed light on possible subtypes of stuttering that respond more or less optimally to AAF (Foundas et al., 2004) to explain this individual variation.

Implications. These findings have important clinical implications. Due to the heterogeneity in responses to the TAD device reflected in this study, it seems important for clinicians not to exclude any potential client expressing an interest in such a device from a fitting and trial period based on any one factor measured in this study, such as stuttering severity, or presence of silent blocks, alone. Similarly, however, it seems equally important to inform potential clients of the variability in responses to AAF and not to make undue promises.

The benefits of the TAD may be enhanced if it is introduced along with other management strategies. These could include behavioural strategies for slowly increasing the length of time using the TAD or grading telephone tasks to increase the likelihood of success and systematically desensitising participants to using the telephone. In addition, speech motor strategies could be given to assist participants in situations where the TAD would not be useful, for example, with silent blocks at the beginning of utterances. It is certainly worthy of future research to investigate whether a more supported and systematic introduction of the TAD within a comprehensive therapy programme addressing telephone avoidances, anxiety, and speech motor techniques would yield more favourable results than those obtained in the present study. This call has been made by other researchers who have found that AAF users tend to combine speech therapy techniques with their AAF devices (Lincoln \& Walker, 2007). Future research is also warranted to investigate the effectiveness of the voice prompting feature of the TAD to assist clients presenting predominantly with silent blocks while talking on the telephone.

\section{ACKNOWLEDGEMENTS}

The author extends grateful thanks to the Dominic Barker Trust for funding this study, and to VoiceAmp for supplying, on loan, the telephone devices and equipment used by the participants. Thanks also go to Penelope Littlejohns for her assistance in coding, Paul Hackney and Pary Kazantzas for assistance in the initial stages of the study, Dilys Jones for helpful discussion of the manuscript, and all the participants, who gave of their time to take part in the study.

\section{REFERENCES}

Antipova, E.A., Purdy, S.C., Blakely, M., \& Williams, S. (2008). Effects of altered auditory feedback (AAF) on stuttering frequency during monologue speech production. Journal of Fluency Disorders. DOI:10.1016/jfludis.2008.09.002.

Armson, J., Kiefte, M., Mason, J.,\& De Croos, D. (2006). The effect of SpeechEasy on stuttering frequency in laboratory conditions. Journal of Fluency Disorders, 31, 137-152.

Bray, M. \& James, S. (2009). An evaluation of a telephone assistive device (TAD) for people who stutter. International Journal of Speech-Language Pathology, 11, 54-60.

Cohen, J. (1960). A coefficient of agreement for nominal scales. Educational and Psychological Measurement, 20, 37-46.

Fleiss, J.L. (1981). Statistical methods for rates and proportions. New York: Wiley.

Foundas, A.L., Bollich, A.M., Feldman, J., Corey, D.M., Hurley, M., Lemen, L.C., et al. (2004). Aberrant auditory processing and atypical planum temporale in developmental stuttering. Neurology, 63, 1640-1646.

James, S.E., Brumfitt, S.M. \& Cudd, P.A. (1999). Communicating by telephone: Views of a group of people with stuttering impairment. Journal of Fluency Disorders, 24, 299-317.

Jankelowitz, D. \& Bortz, M. (1996). The interaction of bilingualism and stuttering in an adult. Journal of Communication Disorders, 29, 223-234.

Kalinowski, J. Armson, J., Mieszkowski, M. R., Stuart, A., \& Gracco, V. L. (1993). Effects of alterations in auditory feedback and speech rate on stuttering frequency. Language and Speech, 36 , $1-16$.

Kalinowski, J., Stuart, A., Sark, S., \& Armson, J. (1996). Stuttering 


\section{Nola Chambers}

amelioration at various auditory feedback delays and speech rates. European Journal of Disorders of Communication, 31, 259-269.

Kiefte, M. \& Armson, J. (2008). Dissecting choral speech: Properties of the accompanist critical to stuttering reduction. Journal of Communication Disorders, 41, 33-48.

Lincoln, M., Packman, A. \& Onslow, M. (2006). Altered auditory feedback and the treatment of stuttering: A review. Journal of Fluency Disorders, 31, 71-89.

Lincoln, M. \& Walker, C. (2007). A survey of Australian adult users of altered auditory feedback devices for stuttering: Use pattern, perceived effectiveness and satisfaction. Disability and Rehabilitation, 29, 1510-1517.

MacLeod, J., Kalinowski, J., Stuart, A., \& Armson, J. (1995). Effect of single and combined auditory feedback on stuttering frequency at two speech rates. Journal of Communication Disorders, 28, 217-228.

O'Donnell, J.J., Armson, J. \& Kiefte, M. (2008). The effectiveness of SpeechEasy during situations of daily living. Journal of Fluency Disorders, 33, 99-119.

Pollard, R., Ellis, J., Finan, D., \& Ramig, P. (2009). Effects of SpeechEasy on objective and perceived aspects of stuttering: A 6-month phase I clinical trial in naturalistic environments. Journal of Speech, Language and Hearing Research, 52, 516-533.

Riley, G.D. (1994). Stuttering Severity Instrument-3. Austin, Texas: Pro-Ed.

Siegel, S. \& Castellan, N.J. (1988). Nonparametric statistics for the behavioral sciences. (2nd Ed.). Boston, MA: McGraw-Hill.

Sparks, G., Grant, D., Millay, K., Walker-Baston, D., \& Hynan, L. (2002). The effect of fast speech rate on stuttering frequency during delayed auditory feedback. Journal of Fluency Disorders, $27,187-201$.

Stuart, A., Kalinowski, J. \& Rastatter, M. P. (1997). Effect of monaural and binaural altered auditory feedback. Journal of the Acoustical Society of America, 101, 3806-3809.

Van Borsel, J., Reunes, G. \& Van den Bergh, N. (2003). Delayed auditory feedback in the treatment of stuttering: clients as consumers. International Journal of Language and Communication Disorders, 38, 119-129.

Van Borsel, J., Sunaert, R. \& Engelen, S. (2005). Speech disruption under delayed auditory feedback in multilingual speakers. Journal of Fluency Disorders, 30, 201-217.

Watt, N. (2000). Analysis of language factors in a multilingual stutterer. South African Journal of Communication Disorders, 47, Special Edition, 5-12.

Wingate, M.E. (1969). Sound and pattern in artificial fluency. Journal of Speech and Hearing Research, 12, 677-686.

Wingate, M.E. (1970). Stuttering and audition. Journal of Speech and Hearing Reşearch, 13, 861-873.

Zimmerman, S., Kalinowski, J., Stuart, A. \& Rastatter, M. (1997). Effect of altered auditory feedback on people who stutter during scripted telephone conversations. Journal of Speech, Language, and Hearing Research, 40, 1130-1134. 